\title{
The Differential Outcomes Effect Using Sensory Outcomes in a Many-to-One Matching-to-Sample Task
}

\author{
Laura Rebeca Mateos Morfín", , Carlos Flores ${ }^{1}, \&$ J. Bruce Overmier ${ }^{2}$ \\ ${ }^{1}$ Universidad de Guadalajara, Mexico \\ ${ }^{2}$ University of Minnesota, United States
}

\begin{abstract}
The present study was designed to evaluate the use of sensory outcomes (visual vs. auditory) using a differential outcomes procedure to facilitate learning in a many-to-one matching-to-sample task. For one group of participants (differential outcomes) each correct stimulus-choice sequence was always followed by a different outcome; whereas for the rest of participants (non-differential outcomes) each correct sequence was followed by the same outcome. Participants trained with differential outcomes showed a faster acquisition and higher overall accuracy than participants trained with non-differential outcomes. The results provide a new extension the differential outcomes effect by using sensory outcomes and many-to-one matching to-sample task; applications of the differential outcomes procedure are discussed.
\end{abstract}

KEYWORDS: differential outcomes effect, conditional discrimination, learning, many-to-one, matching to sample

\section{Consequências Diferenciais Sensoriais em uma Tarefa de Pareamento ao Modelo "Muitos para Um"}

\begin{abstract}
RESUMO - O presente estudo foi delineado para avaliar o uso de consequências sensoriais utilizando um procedimento de consequências diferenciais em uma tarefa de pareamento ao modelo "muitos para um". Para um grupo de participantes, cada sequência correta de escolha de estímulos era sempre seguida por uma consequência diferente; enquanto para os outros participantes, cada sequência correta era seguida pela mesma consequência. Participantes treinados com consequências diferenciais apresentaram aquisição mais rápida e, em geral, maior acurácia do que participantes treinados com consequências não diferenciais. Esses resultados demonstram uma nova extensão do efeito de consequências diferenciais por meio do uso de consequências sensoriais e de uma tarefa de pareamento ao modelo "muitos para um". Aplicações do procedimento de consequências diferenciais são discutidas.
\end{abstract}

PALAVRAS-CHAVE: efeito de consequências diferenciais, discriminação condicional, aprendizagem, muitos-para-um, pareamento ao modelo

Psychology has long been concerned with finding ways to facilitate learning in animals and humans. When in presence of a stimulus (S1) a response (R1) is followed by a particular outcome $(\mathrm{O} 1)$, and in presence of another stimulus (S2) another response (R2) is followed by a different outcome $(\mathrm{O} 2)$, the learning of the discriminative choice task is faster than when both responses are followed by the same outcome. This result is best known as Differential
Outcomes Effect -DOE - (Goeters, Blakely, \& Poling, 1992; Trapold, 1970; Trapold \& Overmier, 1972; Urcuioli, 2005) and it has most commonly been tested using one of several matching-to-sample (MTS) procedures.

Using a conditional discrimination procedure and animals as subjects it has been reported that when different outcomes are correlated with the sample stimuli, not only are the rates of acquisition higher but a higher overall accuracy

*Email: rebecamateos@gmail.com 
is commonly achieved and this accuracy is more persistent in the face of disruptive challenges such as delays or drugs (Hochhalter et al. 2001; Holden \& Overmier, 2014; Savage, Pitkin, \& Careri, 1999).

Some experiments have extended the DOE generality using human subjects (Martella et al. 2012; Miller, Waugh, \& Chambers, 2002; Mok \& Overmier, 2007; Plaza et al. 2012). For example, Maki, Overmier, Delos and Gutmann (1995) reported that children trained in a conditional discrimination procedure with differential outcomes learned more quickly than children trained with non-differential outcomes.

Estévez et al. (2001) extended the study reported by Maki et al. (1995). In their study, Estévez et al. trained children of different ages in conditional discrimination tasks (linear structure) with differential outcomes and non-differential outcomes. The main results were that the children trained with a differential outcomes procedure (DO) learned more quickly than the children trained with a non-differential outcomes procedure (NDO). An interesting result was that older children did not show differences accuracy as indexed by the percentage of correct choices when they compared differential outcomes to non-differential outcomes. The absence of the DOE was interpreted by the authors as a possible ceiling effect, because the task was very easy for the older children. To evaluate this possibility, in a second experiment they used a task that involved a higher degree of complexity by adding two more comparison stimuli. The results of this second experiment showed that the children trained with differential outcomes obtained higher percentages of correct choices than the children trained with the non-differential outcome procedure.

Estévez et al. (2001) increased the degree of complexity by adding more comparison stimuli. Another way to increase the degree of complexity is using a task in which two sample stimuli are related to a one comparison stimulus, and two other samples are related with a different comparison stimulus. In the literature this matching-to-sample procedure has been labeled as many-to-one (MTO). Another procedure is called one-to-many (OTM), in which one sample is related with two comparison stimuli, and another sample stimulus is related with two other comparisons (Arntzen \& Holt, 2000; Arntzen \& Nikolaisen, 2011; Smeets \& Barnes-Holmes, 2005; Smeets, Barnes-Holmes, \& Roche, 2001). Smeets et al. (2001) reported a study in which they compared the three procedures (linear, OTM and MTO) as different ways of training. They found that the number of trials required by the participants to learn the task (training) was greater in the MTO procedure; they did not find differences between the number of trials required by OTM and linear procedures. A similar result was reported by Arntzen and Nikolaisen (2011) when they compared the number of trials required to learn OTM vs. MTO tasks. These results suggest that the MTO is a more challenging task than OTM and linear.
The DOE has been reported using a wide variety of biologically significant outcomes, for example water vs. food, food vs. no food + shock, food vs. sucrose, different types of food (for a review, see Goeters et al. 1992; Urcuioli, 2005), and when the outcomes do not differ in biological significance but do differ in added sensory outcome (Fedorchak \& Bolles, 1986; Friedman \& Carlson, 1973),

However, the DOE has also been reported using outcomes differing in only non-hedonic properties or biologically neutral outcomes. Kelly and Grant (2001) trained pigeons in a delayed matching-to-sample procedure. For one group of pigeons (DO) a peck to the vertical line choice stimulus after the horizontal sample was followed by a blue light as outcome, and a peck to the horizontal line choice after horizontal sample was followed by a yellow light. The correct responses for the NDO group were equally likely to be followed by blue and yellow outcomes. They reported a higher speed learning in subjects trained with the differential outcome procedure. This result extended the DOE when outcomes consist of biologically neutral events.

Studies with human subjects have also reported the DOE using biologically neutral events (sensory outcomes). For example, Mok and Overmier (2007) trained normal human adults in a symbolic or arbitrary matching to sample procedure. In the differential outcomes condition, correct responses were followed by a visual outcome (moving pictures of babies) or by an auditory outcome (a short piece of music) depending on the specific sample-comparison relation; whereas for the non-differential condition (common outcome) the correct responses were followed by a combination of visual and auditory outcomes (a picture of a forest scene and a flute version of the Chinese violin concerto, The Butterfly Lovers). They reported higher percentages of correct responses and a faster rate of learning in the differential outcomes condition than in the common outcomes condition.

Assuming that MTO procedure is more complex or difficult to learn than OTM and based on the fact that participants trained with MTO task require more trials to achieve an accuracy criterion than subjects trained in linear or OTM (Arntzen \& Nikolaisen, 2011; Smeets et al. 2001) and that the DOE has been reported using nonbiologically significant outcomes (Kelly \& Grant, 2001; Mok \& Overmier, 2007). In the present study we used a MTO matching-to-sample task because represent a more challenging task for the subjects according with the results reported by Estévez et al. (2001) and visual vs. auditory outcomes in order to extend the generality of the DOE. This is a novel test of the DOE procedure' effectiveness and could represent an efficient and cheap way for reinforcing complex human behavior in laboratory settings, in contrast with some studies in which the participants earned points and gift cards as outcomes (Johnson, Meleshkevich, \& Dube, 2014; Silveira, Mackay, \& de Rose, 2017). 


\section{METHOD}

\section{Participants}

Forty students (aged 19 to 22 years) participated in the study; their participation was voluntary and they did not have any history with the task; all of them provided written informed consent before participating in the study. Twenty-four were females and sixteen were males. Twenty participants formed the differential outcomes group (DO) while the rest formed the non-differential outcomes group (NDO); the assignment of the participants to the groups was carried out randomly. The participants signed the informed consent, all procedures performed in this study were in accordance with the ethical standards of the institutional and national research committee.

\section{Materials and Apparatus}

Two compatible IBM computers were used equipped with a 15 -inch color monitor. The programs were written using the software SuperLab Pro ver 5.0 (Cedrus Software Corporation); the responses were registered by clicks of the mouse button (left).

\section{Procedure}

At the beginning of each trial a black point was shown in the center of the monitor with a duration of $0.5 \mathrm{~s}$ (i.e., Fixation Point); after that a sample stimulus was presented with a $1.5 \mathrm{~s}$ duration. The sample stimulus consisted of one of four rectangles that differed in color (yellow, blue, red or green), each measuring $32 \times 38 \mathrm{~mm}$ (length X width). Immediately after the termination of the sample, two rectangles with the same dimensions, appearing on either side of the fixation point, and these served as comparison stimuli. One of them was white and the other was black; they were $14 \mathrm{~mm}$ away from the fixation point on the horizontal plane. The duration of the comparison stimuli depended on the moment in which the subject emitted a choice response on the stimulus (pressing the left button of the mouse while hovering over the selected colored box). Two sample stimuli (yellow and green) required a click to the black rectangle; the other two samples (red and blue) required a click to the white rectangle. For 10 participants in the differential group, choosing the black rectangle after being presented with yellow or green rectangles had a recorded voice that said "CORRECT" as an outcome ( $2 \mathrm{~s}$ duration); the selection of the white rectangle after being presented with the red or blue rectangle had the printed word "CORRECT" on the monitor as an outcome ( $2 \mathrm{~s}$ duration). For the other ten participants in the differential outcomes treatment the correlation of the sample stimuli, comparison choices, and the outcome was counterbalanced. For ten participants in the non-differential outcomes group, the outcomes were the recorded voice "CORRECT", independently of the positive combination of stimuli. For the other ten of the participants in the DO group, the consequence was the printed word "CORRECT" shown on the monitor. When any subject in any treatment group chose the incorrect comparison stimulus they received a blank screen for a duration of $2 \mathrm{~s}$, and the next trial began after $4 \mathrm{~s}$ intertrial interval.

The session consisted of 80 trials, counterbalancing the presentation of the sample stimuli and the position of the comparison stimuli. Performance accuracy was indexed by percentage of correct choices. A significance level of .05 ( $p$ $<0.05$ ) was used for the statistical analyses.

\section{RESULTS}

The mean of correct responses (overall accuracy) obtained in each group is shown in Figure 1. The group trained with differential outcomes obtained a higher percent of correct responses than the group trained with non-differential outcomes (differential: $M=84.46, S E M=$ 2.03; non-differential: $M=72.85, S E M=1.15$ ). Unpaired $t$ test confirmed overall difference between groups, $t$ (38) $=-4.966, p<.001, d=1.836, r=.676$; the group trained with differential outcomes achieved a higher overall mean of correct choices than the group trained with non-differential outcomes.

The percentages of correct responses for each group (mean of ten trials in each block) are shown in Figure 2. Differences were observed in the percentages of correct responses between the differential and the non-differential

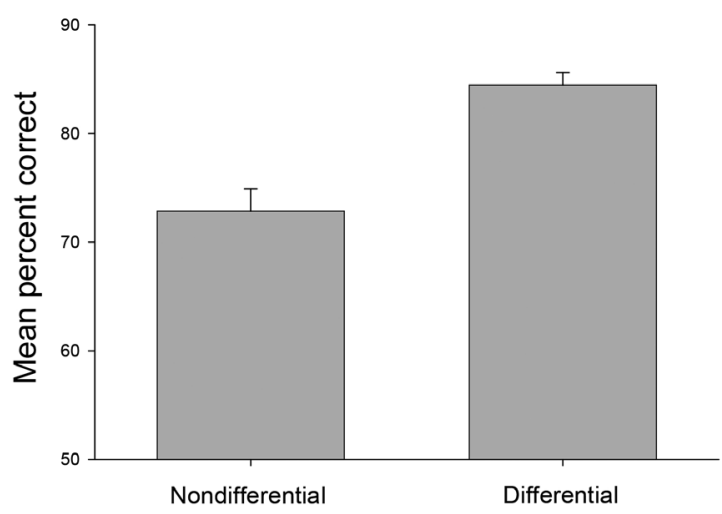

Figure 1. Overall percentage of correct choices for the differential outcomes and nondifferential outcomes groups; bars represent the standard error of mean. 
outcomes groups with the mean differences in percentages correct seen from block two onward. The differential outcomes group showed a higher rate of acquisition than the non-differential group; also the terminal levels of accuracy were higher in the differential group than in the non-differential group. A one between-subjects (group) and one within-subjects (blocks of trials) repeated measures analysis of variance ANOVA showed a main effect of group (differential vs. non-differential), $F(1,38)=24.66, p<.001$, $\eta^{2}=.487$ and a main effect of blocks, $F(1,7)=63.91, p$ $<.001, \eta^{2}=.711$, respectively. There was also a Group $\mathrm{x}$ Block interaction, $F(1,7)=2.63, p=.013, \eta^{2}=.092$. While the two groups began at similar levels of performance, the mean of correct responses during the last two blocks was $M$ $=96.07, S E M=0.93$ for the differential group, whereas for the non-differential group it was $M=89.64, S E M=1.49, t$ $(38)=-3.635, p<.001, d=.972, r=.437$.

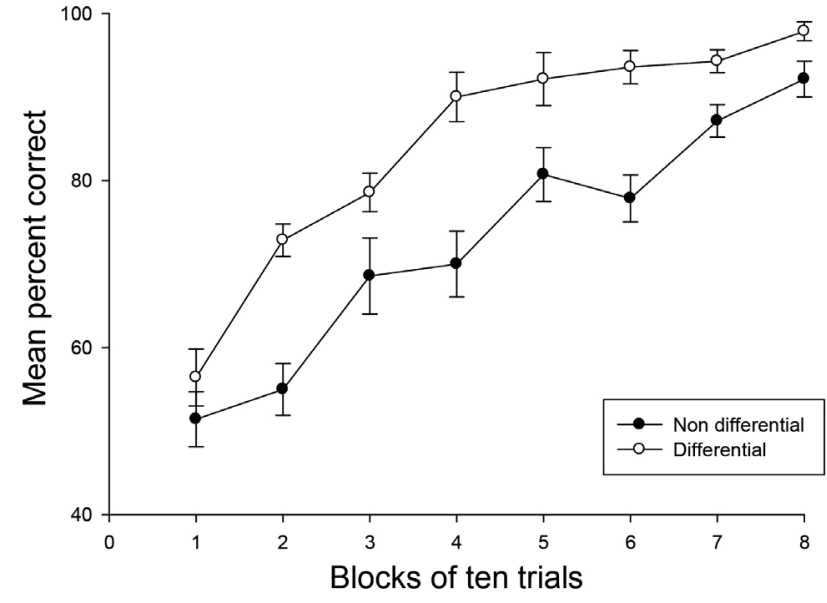

Figure 2. Percentage of correct choices in blocks of 10 trials, differential outcomes (white circles), nondifferential outcomes (black circles); bars represent the standard error of mean.

\section{DISCUSSION}

The present study was designed with the purpose of evaluating whether differential outcomes of visual and auditory feedback outcomes facilitate the learning in an MTO matching-to-sample task. The main result was that the participants trained with a differential outcome procedure showed faster learning and higher accuracy than participants trained with non-differential outcomes. This result extends the generality of DOE when sensory outcomes are used (Estévez et al. 2007; Mok \& Overmier, 2007). For example, Estévez et al. (2007) trained participants with difficulties in the correct use of the mathematical symbols "> and " $<$ ". Participants trained with differential outcomes (hearing "GREAT!" vs. a brief melody) showed a higher accuracy than the participants trained with non-differential outcomes.

A relevant aspect in the present study is that the DOE was observed in an MTO task; this finding supports the idea that a more complex task is necessary to observe the DOE when sensory outcomes are used (Estévez et al. 2001). The highest degree of complexity on the MTO task is based on the studies that have reported a higher number of trials are required to achieve a learning (or accuracy) criterion when an MTO task is used compared with linear or OTM tasks (Arntzen \& Nikolaisen, 2011; Smeets et al. 2001).

MTO, OTM and linear tasks have been used to evaluate equivalence class formation (Sidman \& Tailby, 1982; Sidman, 2000). Some studies have reported that the use of differential outcomes procedure has also been used to test the emergence of equivalence classes (Dube et al. 1989; Goyos, 2000; Johnson et al. 2014; Minster, Jones, Elliffe, \& Muthukumaraswamy, 2006; Monteiro \& Barros, 2016; Schenk, 1994; Silveira \& de Rose, 2015; Silveira et al. 2017; Varella \& de Souza, 2014). For example, Dube et al. (1989) used food vs. drink as outcomes, Schenk (1994) used red beads vs. blue beads, Goyos (2000) used red tokens vs. yellow tokens that could be exchanged for video cartoons or for small toys, Johnson et al. (2014) used tokens with different colors, Monteiro and Barros (2016) used different sounds correlated to each class, Silveira and de Rose (2015) and Silveira et al. (2017) correlated specific images and sounds to each class, and Varella and de Souza, (2014) used different edible reinforces and sounds. In their study Silveira and de Rose (2015) did not found the formation of equivalence relations using non-biological outcomes, they explained their results assuming a lack of reinforcing properties of the outcomes used and suggested that nonbiological outcomes were not efficient for reinforcing the behavior of typical adults in laboratory settings. In contrast, in the present study the use of non-biological outcomes seem to be reinforcing properties and showed a robust effect by the use of differential outcomes procedure. It is probably that the differences in the results reported by Silveira and de Rose (2015) and the present study could be explained attending to the type of task and outcomes.

The evaluation of DOE or the use of class-specific neutral "reinforcers" show a potential that this procedure could have in educational contexts. For example, Mok, Estévez and Overmier (2010) reported a paper in which they highlighted the potential for the use of differential outcomes training as a powerful pedagogical tool to improve learning and memory. Indeed, Miller et al. (2002) evaluated the effectiveness of differential outcomes procedure in learning Japanese symbols (Kanji) in college students. They identified that students who were trained with differential outcomes showed a higher percentage of correct responses than the students trained in a non-differential outcomes procedure. These results were replicated by Easton, Child and LópezCrespo (2011) to learn kanji symbols and to form categories. 
It is possible as well that use of this procedure can contribute also in the research about and the treatment or amelioration of disorders related to impaired learning and memory as a consequence of age (López-Crespo, Plaza, Fuentes, \& Estévez, 2009; Mateos \& Flores, 2016; Mateos, Madrigal, Flores, \& Overmier, 2016; Savage et al. 1999) or with syndromes associated with memory deficits (Esteban et al. 2014; Plaza et al. 2012), and treatment of other disorders, for example, the treatment associated with sleep deprivation disorders (Martella et al. 2012).

In summary, the current paper provides evidence in a new task for the differential outcomes effect using neutral outcome events such as might be commonly adapted for use with human clients needing support for their learning of challenging discriminations.

\section{REFERENCES}

Arntzen, E., \& Holth, P. (2000). Differential probabilities of equivalence outcome in individual subjects as a function of training structure. The Psychological Record, 50, 79-104. doi:10.1007/BF0339537

Arntzen, E., \& Nikolaisen, S. L. (2011). Establishing equivalence classes in children using familiar and abstract stimuli and many-to-one and one-to-many training structures. European Journal of Behavior Analysis, 12, 105-120.

Dube, W. V., McIlvane, W. J., Maguire, R. W., Mackay, H. A., \& Stoddard, L. T. (1989). Stimulus class formation and stimulusreinforcer relations. Journal of the Experimental Analysis of Behavior, 51, 66-76. doi:10.1901/jeab.1989.51-65

Easton, A., Child, S., \& López-Crespo, G. (2011). Differential outcomes aid the formation of categorical relationships between stimuli. Behavioural Brain Research, 222, 270-273. doi:10.1016/j.bbr.2011.03.036

Esteban, L., Plaza, V., López-Crespo, G., Vivas, A. B., \& Estévez, A. F. (2014). Differential outcomes training improves face recognition memory in children and in adults with Down syndrome. Research in Developmental Disabilities, 35, 13841392. doi:10.1016/j.ridd.2014.03.031

Estévez, A. F., Fuentes, L. J., Marí-Beffa, P., González, C., \& Álvarez, D. (2001). The differential outcome effect as a useful tool to improve conditional discrimination learning in children. Learning and Motivation, 32, 48-64. doi:10.1006/ lmot.2000.1060

Estévez, A. F., Vivas, A. B., Alonso, D., Marí-Beffa, P., Fuentes, L. J., \& Overmier, J. B. (2007). Enhancing challenged students recognition of mathematical relations through differential outcomes training. The Quarterly Journal of Experimental Psychology, 60, 571-580. doi:10.1080/17470210600820039

Fedorchak, P. M., \& Bolles, R. C. (1986). Differential outcome effect using a biologically neutral outcome difference. Journal of Experimental Psychology: Animal Behavior Processes, 12, 125-130. doi:10.1037/0097-7403.12.2.125

Friedman, G. J., \& Carlson, J. G. (1973). Effects of a stimulus correlated with positive reinforcement upon discrimination learning. Journal of Experimental Psychology, 97, 81-286. doi: $10.1037 / \mathrm{h} 0034123$

Goeters, S., Blakely, E., \& Poling, A. (1992). The differential outcomes effect. The Psychological Record, 42, 389-411.

Goyos, C. (2000). Equivalence class formation via common reinforcers among preschool children. The Psychological Record, 50, 629-654. doi:10.1007/BF03395375

Hochhalter, A. K, Sweeney, W. A., Savage, L. M., Bakke, B. L., \& Overmier, J. B. (2001). Using animal models to address the memory deficits of Wernicke-Korsakoff syndrome. In M. E. Carroll \& J. B. Overmier (Eds.), Animal Research and human health. (pp. 281-292). Washington: American Psychological Association.

Holden, J. M., \& Overmier, J. B. (2014). Performance under differential outcomes: Contributions of reward-specific expectancies. Learning and Motivation, 45, 1-14. doi:10.1016/j. lmot.2013.09.001

Johnson, C., Meleshkevich, O., \& Dube, W. V. (2014). Merging separately established stimulus classes with outcome-specific reinforcement. Journal of the Experimental Analysis of Behavior, 101, 38-50. doi: 10.1002/jeab.61

Kelly. R., \& Grant, D. S. (2001). A differential outcomes effect using biologically neutral outcomes in delayed matching-tosample with pigeons. The Quarterly Journal of Experimental Psychology, 54, 69-79.

López-Crespo, G., Plaza, V., Fuentes, L. J., \& Estévez, A. F. (2009). Improvement of age-related memory deficits by differential outcomes. International Psychogeriatrics, 21, 503-510. doi:10.1017/S1041610209008576

Maki, P., Overmier, J. B., Delos, S., \& Gutmann, A. J. (1995). Expectancies as factors influencing conditional discrimination performance of children. The Psychological Record, 45, 45-71.

Martella, D., Plaza, V., Estévez, A. F., Castillo, A., \& Fuentes, L. J. (2012). Minimizing sleep deprivation effects in healthy adults by differential outcomes. Acta Psychologica, 139, 391-396. doi:10.1016/j.actpsy.2011.12.013

Mateos, L. R., \& Flores, C. (2016). The differential outcomes effect: A case of translational research. Universitas Psychologica, 15, 51-60. doi:10.11144/Javeriana.upsy15-2.ecdc

Mateos, L. R., Madrigal, K., Flores, C., \& Overmier, J. B. (2016). The effects of differential outcomes on learning and memory in young and aged rats. Learning and Motivation, 53, 1-6. doi:10.1016/j.lmot.2015.10.004

Miller, O., Waugh, K, \& Chambers, K. (2002). Differential outcomes effect: Increased accuracy in adults learning Kanji with stimulus specific rewards. The Psychological Record, $52,315-324$.

Minster, S. T., Jones, M., Ellife, D., \& Mathukumaraswamy, S. D. (2006). Stimulus equivalence: Testing Sidman's (2000) theory. Journal of the Experimental Analysis of Behavior, 85, 371-391. doi:10.1901/jeab.2006.15-05

Mok, L. W., Estévez, A. F., \& Overmier, J. B. (2010). Unique outcome expectations as a training and pedagogical tool. The Psychological Record, 60, 227-248.

Mok, L. W., \& Overmier, J. B. (2007). The differential outcomes effect in normal human adults using a concurrent-task withinsubject design and sensory outcomes. The Psychological Record, 57, 187-200.

Monteiro, P. C. M., \& Barros, R. S. (2016). Emergence of auditoryvisual relations via equivalence class formation in children diagnosed with autism. The Psychological Record, 66, 563-571. doi: 10.1007/s40732- 016-0192-1

Plaza, V., Antúnez, C., Estévez, A. F., López-Crespo, G., \& Fuentes, L. J. (2012). Improving delayed face recognition in Alzheimer`s disease by differential outcomes. Neuropsychology, 4, 482-489. doi: $10.1037 / \mathrm{a} 0028485$

Savage, L. M., Pitkin, S. R., \& Careri, J. M. (1999). Memory enhancement in aged rats: The differential outcomes effect. 
Developmental Psychobiology, 35, 318-327. doi:10.1002/ (SICI) 1098-2302(199912)35:4<318::AID-DEV6>3.0.CO;2-8

Schenk, J. L. (1994). Emergent relations of equivalence generated by outcome-specific consequences in conditional discrimination. The Psychological Record, 44, 537-558.

Sidman, M. (2000). Equivalence relations and the reinforcement contingency. Journal of the Experimental Analysis of Behavior, 74, 127-146. doi:10.1901/jeab.2000.74-127

Sidman, M., \& Tailby, W. (1982). Conditional discrimination vs. matching to sample: An expansion of the testing paradigm. Journal of the Experimental Analysis of Behavior, 37, 5-22. doi:10.1901/jeab.1982.37-5

Silveira, M. V., Mackay, H. A., \& de Rose, J. C. (2017). Measuring the "transfer of meaning" through members of equivalence classes merged via a class-specific reinforcement procedure. Learning \& Behavior, 46, 157-170. doi: 10.3758/s13420017-0298-6

Silveira, M. V., \& de Rose, J. C. (2015). Consequências específicas arbitrárias em matching de identidades são efetivas para o estabelecimento de classes de equivalência? Revista Brasileira de Análise do Comportamento, 11, 61-69.

Smeets, P. M., \& Barnes-Holmes, D. (2005). Establishing equivalence classes in preschool children with one-to-many and many-to-one training protocols. Behavioural Processes, 69, 281-293. doi:10.1016/j.beproc.2004.12.009

Smeets, P. M., Barnes-Holmes, D. \& Roche, B. (2001). Derived stimulus-response and stimulus-stimulus relations in children and adults: Assessing training order effects. Journal of Experimental Child Psychology, 78, 130-154. doi:10.1006/ jecp. 2000.2563

Trapold, M. A. (1970). Are expectancies based upon different positive reinforcing events discriminably different? Learning and Motivation, 1, 129-140. doi:10.1016/00239690(70)90079-2

Trapold, M. A., \& Overmier, J. B. (1972). The secondary learning process in instrumental learning. In A. H. Black \& W.F. Prokasy (Eds.), Classical conditioning: Vol 2. Current Research and Theory. New York: Appleton.

Urcuioli, P. J. (2005). Behavioral and associative effects of differential outcomes in discrimination learning. Learning and Behavior, 33, 1-21. doi:10.3758/BF03196047

Varella, A. A. B., \& de Souza, D. G. (2014). Emergence of auditoryvisual relations from a visual-visual baseline with auditory-specific consequences in individuals with autism. Journal of the Experimental Analysis of Behavior, 102, 139-149. doi: 10.1002/jeab.93

Submitted: 16/02/2018

Reviewed: 30/07/2018

Accepted: 03/09/2018 